\title{
Determination of Tetrathionate, Thiosulfate, Sulfite and Trithionate in Their Mixtures by Spectrophotometry
}

\author{
Tomozo KoH, Yasuyuki MiUra, Masahiro Ishimori and Norihito YamamUro \\ Department of Chemistry, Faculty of Science, Tokai University, Hiratsuka, Kanagawa 259-12, Japan
}

\begin{abstract}
The proposed method consists of four procedures; excess iodine for reactions with thiosulfate and/or sulfite under Procedures I, II and III, and the thiocyanate formed under Procedure IV are measured spectrophotometrically after proper chemical treatments. The absorbance obtained by Procedure I corresponds to the sum of the amount of tetrathionate and that of thiosulfate in the mixture. The absorbance obtained by Procedure II corresponds only to the amount of thiosulfate in the mixture. The absorbance obtained by Procedure III corresponds to the sum of the amount of thiosulfate and twice that of sulfite in the mixture. The absorbance obtained by Procedure IV corresponds to the sum of the amount of both thiosulfate and trithionate and twice that of tetrathionate in the mixture. The proposed method was applied to the determination of tetrathionate, thiosulfate, sulfite and trithionate mixed in various ratios in amounts of more than $0.05 \mu \mathrm{mol}$ with an error below $\pm 0.02 \mu \mathrm{mol}$.
\end{abstract}

Keywords Polythionates determination, tetrathionate sulfitolysis, trithionate cyanolysis, tetrathionate-trithionatethiosulfate-sulfite mixture, spectrophotometry

The determination of various sulfur anion species in their mixtures is desirable for interpreting their redox chemistry in aqueous solution systems. However, this is difficult owing to similarities in their chemical and physical properties. Spectrophotometric methods ${ }^{1,2}$ for the determination of trithionate, thiosulfate and tetrathionate in a mixture, based on the formation of thiocyanate by their cyanolysis, have been proposed. In an experiment the cyanolysis of trithionate was carried out at pH 9.6 for $30 \mathrm{~min}$ at a temperature of boiling water. Under these conditions, only $87 \%$ of trithionate was converted into thiocyanate, the rest into thiosulfate. Accordingly, these methods can not be considered accurate. Recently, a number of publications dealing with high performance liquid chromatography (HPLC) for the separation of mixtures of polythionates have appeared. ${ }^{3-10}$ However, no consideration has been given to the determination of tetrathionate, thiosulfate, sulfite and trithionate in a mixture.

The present authors have developed methods for the determination of tetrathionate ${ }^{11}$, pentathionate ${ }^{12}$ and hexathionate ${ }^{13}$ by means of their sulfitolysis. On the other hand, lanthanum(III) has been found to have a catalytic effect on the conversion of trithionate ${ }^{14}$ and thiosulfate ${ }^{15}$ into thiocyanate. In this work, the conditions under which both thiosulfate and trithionate are simultaneously and completely converted into thiocyanate were established. This paper is concerned with the sulfitolysis of tetrathionate and the cyanolysis of both thiosulfate and trithionate for the determination of four sulfur species of tetrathionate, thiosulfate, sulfite and trithionate in a mixture.

\section{Experimental}

\section{Reagents and apparatus}

All chemicals used, except tetrathionate and trithionate, were of analytical grade and used without further purification. The water used in these experiments was redistilled. Potassium tetrathionate was prepared according to a procedure described by Stamm et al. ${ }^{16}$ The obtained tetrathionate was further recrystallized with water at temperatures below $60^{\circ} \mathrm{C}$ and then dried at room temperature before storage at $-10 \pm 2^{\circ} \mathrm{C}$. A standard tetrathionate solution $\left(1 \times 10^{-3} \mathrm{M}\right)$ was prepared by dissolving $151.3 \mathrm{mg}$ of the potassium tetrathionate (water content: $0.07 \%$ ) in water and diluting to $500 \mathrm{ml}$. The concentration of the tetrathionate solution was checked by the sulfitolysis method" and the solution stored at $5 \pm 2^{\circ} \mathrm{C}$. A stock solution of thiosulfate was prepared by dissolving a known amount of sodium thiosulfate pentahydrate in oxygen-free water containing a small amount of sodium carbonate as a stabilizer. It was standardized by iodometry ${ }^{17}$ one week after preparation. Working standard thiosulfate solutions were prepared by suitable dilution with oxygen-free water. These standards were used to ascertain the stoichiometry and completion of the sulfitolysis of tetrathionate. A sulfite solution was 
prepared by dissolving sodium hydrogen sulfite in oxygen-free water and standardized by iodometry. ${ }^{17}$ Working standards were obtained by suitable dilutions with oxygen-free water. A $0.15 \mathrm{M}$ sulfite solution, which was not standardized, proved to be useful for the sulfitolysis of tetrathionate for 2 weeks after its preparation. A thiocyanate solution was standardized by the Volhard method ${ }^{18}$, and working standards were prepared by suitable dilution. These standards were used to ascertain the stoichiometry of the cyanolysis of thiosulfate and trithionate. Potassium trithionate was prepared according to a procedure described by Stamm et al. ${ }^{16}$ The obtained trithionate was recrystallized with water at a temperature below $35^{\circ} \mathrm{C}$ and then dried at room temperature before storage at $-10 \pm 2^{\circ} \mathrm{C}$. A trithionate solution was standardized against a standard thiocyanate solution by the cyanolysis method; ${ }^{14}$ the solution was stored at $5 \pm 2^{\circ} \mathrm{C}$. A standard iodateiodide solution was prepared by adding $50.0 \mathrm{ml}$ of $1.00 \times 10^{-2} \mathrm{~N}\left(=1.67 \times 10^{-3} \mathrm{M}\right)$ standard iodate to a solution containing $0.2 \mathrm{~g}$ of sodium carbonate and $72.6 \mathrm{~g}$ of potassium iodide, and diluting it to $500 \mathrm{ml}$ to give a $1.00 \times 10^{-3} \mathrm{~N}$ iodate in a $0.87 \mathrm{M}$ iodide solution.

Then, $1.5 \mathrm{M}$ iron(III) in a $4 \mathrm{M}$ perchloric acid solution was prepared by dissolving $306.05 \mathrm{~g}$ of iron(III) nitrate nonahydrate $(99 \%)$ in a small volume of water containing $217.4 \mathrm{ml}$ of $60 \%$ perchloric acid and diluting it to $500 \mathrm{ml}$. The buffer solutions of pH 9.9 used in Procedures I, II and IV and of pH 3.5 used in Procedures I and II were prepared by mixing $100 \mathrm{ml}$ of $0.3 \mathrm{M}$ sodium hydrogencarbonate with $100 \mathrm{ml}$ of $0.3 \mathrm{M}$ sodium carbonate, and $160 \mathrm{ml}$ of $0.5 \mathrm{M}$ acetic acid with $10 \mathrm{ml}$ of $0.5 \mathrm{M}$ sodium acetate, respectively.

All spectrophotometric measurements were made with a Shimadzu Model UV-100-02 spectrophotometer with 10-mm quartz cells. The $\mathrm{pH}$ was measured with a Hitachi-Horiba Model M-7 pH meter.

\section{Procedure}

The proposed method for the determination of tetrathionate, thiosulfate, sulfite and trithionate in mixtures consists of the following four procedures.

Procedure I. For total amounts of tetrathionate and thiosulfate in the mixture. Pipette $1.8 \mathrm{ml}$ of the carbonate buffer solution ( $\mathrm{pH} 9.9$ ), $2 \mathrm{ml}$ of the $0.15 \mathrm{M}$ sulfite solution, and then a $10-\mathrm{ml}$ aliquot of a sample solution containing tetrathionate, thiosulfate, sulfite and trithionate, into a $25-\mathrm{ml}$ volumetric flask. The pH of the solution is thereby brought to 8.0. Allow the mixture to stand at room temperature for $20 \mathrm{~min}$, to completely convert tetrathionate into thiosulfate. Add $2 \mathrm{ml}$ of $0.5 \mathrm{M}$ formaldehyde solution and $1.5 \mathrm{ml}$ of the acetate buffer solution (pH 3.5) to the reaction mixture. In this case, the solution was buffered to a $\mathrm{pH}$ of 5.0 . Allow the mixture to stand for $5 \mathrm{~min}$ to completely mask any excess sulfite.

Precedure II. For amounts of thiosulfate in the mixture. Place $1.8 \mathrm{ml}$ of the carbonate buffer solution (pH 9.9), a 10-ml aliquot of the above sample solution,
$2 \mathrm{ml}$ of the $0.5 \mathrm{M}$ formaldehyde solution and $1.5 \mathrm{ml}$ of the acetate buffer solution ( $\mathrm{pH} \mathrm{3.5)}$ in a 25-ml volumetric flask. Then allow the mixture to stand for $5 \mathrm{~min}$ to completely mask any sulfite in the sample.

Procedure III. For total amounts of thiosulfate and sulfite in the mixture. Pipette a $10-\mathrm{ml}$ aliquot of the sample solution into a $25-\mathrm{ml}$ volumetric flask.

To these three mixture solutions from Procedures I, II and III, add $2 \mathrm{ml}$ of $5 \mathrm{M}$ acetic acid and $2.4 \mathrm{ml}$ of the standard $1.00 \times 10^{-3} \mathrm{~N}$ iodate in a $0.87 \mathrm{M}$ iodide solution; then dilute to the mark with water. Mix the contents of the flask well and measure the absorbance of the solution against water at $350 \mathrm{~nm}$ of maximum absorption for triiodide ion.

Procedure IV. For total amounts of tetrathionate, thiosulfate and trithionate in the mixture. Pipette $1.8 \mathrm{ml}$ of the carbonate buffer solution ( $\mathrm{pH} \mathrm{9.9),} 2 \mathrm{ml}$ of the $0.15 \mathrm{M}$ sulfite solution and a $10-\mathrm{ml}$ aliquot of the sample solution into a $50-\mathrm{ml}$ volumetric flask. Allow the mixture to stand for $20 \mathrm{~min}$ in order to sulfitolyze the tetrathionate completely. Then add $0.6 \mathrm{ml}$ of $0.5 \mathrm{M}$ acetic acid and $2 \mathrm{ml}$ of $0.5 \mathrm{M}$ formaldehyde to the reaction mixture, and allow the mixture to stand for $5 \mathrm{~min}$ to mask the sulfite. To this mixture add $2 \mathrm{ml}$ of $1 \mathrm{M}$ acetic acid, $1.5 \mathrm{ml}$ of $1.5 \mathrm{M}$ lanthanum(III) nitrate and $4.5 \mathrm{ml}$ of $4 \mathrm{M}$ cyanide solution; the resulting solution has a $\mathrm{pH}$ of 9.5 . Allow the mixture to stand at $15^{\circ} \mathrm{C}$ for $1.5 \mathrm{~h}$ in order to completely convert both the thiosulfate and the trithionate into thiocyanate. Then add $1 \mathrm{ml}$ of $0.01 \mathrm{M}$ iodine in methanol, $4 \mathrm{ml}$ of $60 \%$ perchloric acid and $3 \mathrm{ml}$ of $1.5 \mathrm{M}$ iron(III) nitrate in a $4 \mathrm{M}$ perchloric acid solution. Dilute to the mark with water, mix the contents well and measure the absorbance of the solution of the iron(III)-thiocyanate complex, thus formed, against water at $460 \mathrm{~nm}$.

\section{Results and Discussion}

\section{Calibration graphs}

It is well known that polythionates do not consume iodine, but that thiosulfate and sulfite react with iodine in an acidic medium as follows:

$$
\begin{aligned}
& 2 \mathrm{~S}_{2} \mathrm{O}_{3}^{2-}+\mathrm{I}_{2} \rightarrow \mathrm{S}_{4} \mathrm{O}_{6}{ }^{2-}+2 \mathrm{I}^{-} \\
& \mathrm{SO}_{3}{ }^{2-}+\mathrm{I}_{2}+\mathrm{H}_{2} \mathrm{O} \rightarrow \mathrm{SO}_{4}^{2-}+2 \mathrm{I}^{-}+2 \mathrm{H}^{+}
\end{aligned}
$$

In a previous paper"1, the conditions under which tetrathionate is converted into thiosulfate according to

$$
\mathrm{S}_{4} \mathrm{O}_{6}{ }^{2-}+\mathrm{SO}_{3}{ }^{2-} \longrightarrow \mathrm{S}_{2} \mathrm{O}_{3}^{2-}+\mathrm{S}_{3} \mathrm{O}_{6}{ }^{2-}
$$

have been established, in which $1 \mathrm{~mol}$ of thiosulfate is formed by the sulfitolysis of $1 \mathrm{~mol}$ of tetrathionate. It can be seen in Fig. 1 that the calibration graph for the tetrathionate obtained by Procedure I, that for the thiosulfate obtained by Procedure II and that for the sulfite obtained by Procedure III were, respectively, in good agreement with one another when the molar 


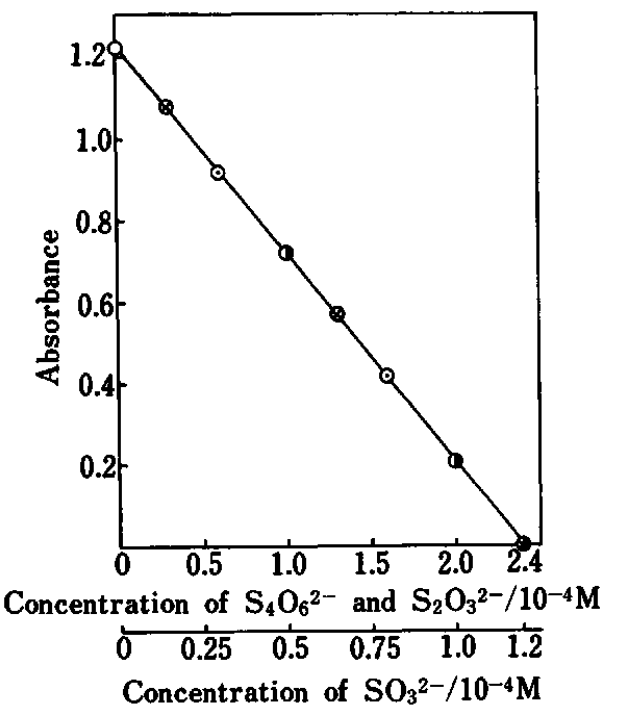

Fig. 1 Calibration graphs for tetrathionate, thiosulfate and sulfite obtained by Procedures I, II and III. O, reagent blank obtained by Procedures I, II and III; $\odot, \mathrm{S}_{4} \mathrm{O}_{6}{ }^{2-}$ by Procedure I; $\otimes, \mathrm{S}_{2} \mathrm{O}_{3}{ }^{2-}$ by Procedures I, II and III; $O$, $\mathrm{SO}_{3}^{2-}$ by Procedure III.

Table 1 Effect of formaldehyde on the cyanolysis of thiosulfate and trithionate

\begin{tabular}{ccccc}
\hline & \multicolumn{4}{c}{ Absorbance } \\
\cline { 2 - 5 } Sample & \multicolumn{3}{c}{ In the absence of HCHO } & $0.5 \mathrm{M}$ HCHO $2 \mathrm{ml}^{\mathrm{a}}$ \\
& $8 \times 10^{-4} \mathrm{M}$ & $12 \times 10^{-4} \mathrm{M}$ & $8 \times 10^{-4} \mathrm{M}$ & $12 \times 10^{-4} \mathrm{M}$ \\
\hline $\mathrm{SCN}^{-}$ & $0.675^{\mathrm{b}}$ & $1.011^{\mathrm{b}}$ & $0.670^{\mathrm{b}}$ & $1.005^{\mathrm{b}}$ \\
$\mathrm{S}_{2} \mathrm{O}_{3}{ }^{2-}$ & 0.668 & 0.987 & 0.670 & 1.000 \\
$\mathrm{~S}_{3} \mathrm{O}_{6}{ }^{2-}$ & 0.677 & 1.011 & 0.670 & 1.000 \\
\hline
\end{tabular}

a. Under the same conditions as in Procedure IV.

b. The expected values obtained for thiocyanate.

concentration scale for sulfite was drawn to twice the concentration scale for tetrathionate and thiosulfate. Experimental results revealed that tetrathionate does not react at all with the sulfite in the sample solution under Procedures II and III, but is stoichiometrically converted into thiosulfate according to Eq. (3) under Procedure I.

According to Eq. (3), when $1 \mathrm{~mol}$ of tetrathionate undergoes sulfitolysis, $1 \mathrm{~mol}$ of thiosulfate and trithionate, each, is formed. Lanthanum(III) has been found to have a catalytic effect on the following reactions of thiosulfate ${ }^{15}$ and trithionate: ${ }^{14}$

$$
\begin{aligned}
& \mathrm{S}_{2} \mathrm{O}_{3}{ }^{2-}+\mathrm{CN}^{-} \rightarrow \mathrm{SO}_{3}{ }^{2-}+\mathrm{SCN}^{-} \\
& \mathrm{S}_{3} \mathrm{O}_{6}{ }^{2-}+3 \mathrm{CN}^{-}+\mathrm{H}_{2} \mathrm{O} \rightarrow \underset{\mathrm{SO}_{3}{ }^{2-}}{\mathrm{SCN}^{-}}-\mathrm{SO}_{4}{ }^{2-}+2 \mathrm{HCN}+
\end{aligned}
$$

The results obtained for the cyanolysis of thiosulfate and trithionate are shown in Table 1. When a 2-ml volume of $0.5 \mathrm{M}$ formaldehyde was deleted from

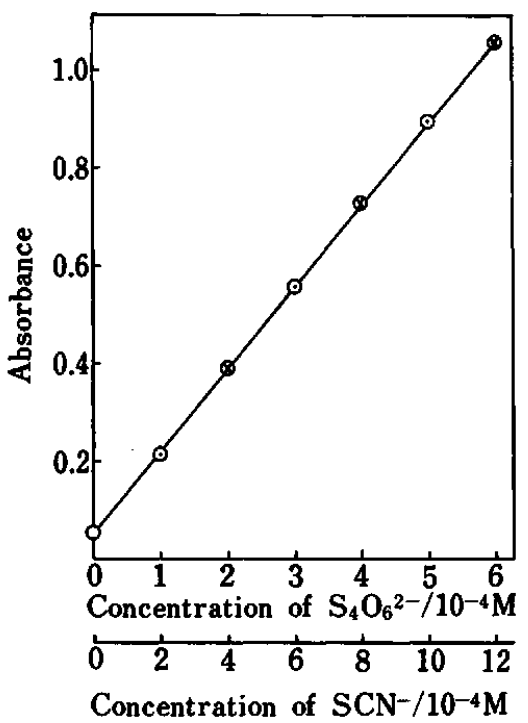

Fig. 2 Calibration graphs for tetrathionate and thiocyanate obtained by Procedure IV. $\mathrm{O}$, reagent blank; $\odot, \mathrm{S}_{4} \mathrm{O}_{6}{ }^{2-} ; \otimes$, $\mathrm{SCN}^{-}$

Procedure IV, thiosulfate gave lower absorbances than the expected values, in which the excess sulfite used for the sulfitolysis of tetrathionate interfered with the cyanolysis of thiosulfate. Thiosulfate and trithionate were quantitatively converted into thiocyanate over the $\mathrm{pH}$ ranges 9.3-9.6 and 8.9-9.6, respectively, when cyanolyzed for $1.5 \mathrm{~h}^{15}$ at $15^{\circ} \mathrm{C}^{14}$ after complete masking of the excess sulfite with formaldehyde in the solution buffered at the $\mathrm{pH}$ range 4.0-9.1.12 Consequently, both of the thiosulfate and trithionate formed from tetrathionate and those in the sample could be stoichiometrically converted into thiocyanate over the $\mathrm{pH}$ range 9.39.6. The overall reaction for tetrathionate under Procedure IV is as follows:

$$
\begin{aligned}
\mathrm{S}_{4} \mathrm{O}_{6}{ }^{2-}+4 \mathrm{CN}^{-}+\mathrm{H}_{2} \mathrm{O} \rightarrow & \mathrm{SO}_{3}^{2-}+\mathrm{SO}_{4}^{2-}+2 \mathrm{HCN} \\
& +2 \mathrm{SCN}^{-} .
\end{aligned}
$$

Here, $1 \mathrm{~mol}$ of tetrathionate produces $2 \mathrm{~mol}$ of thiocyanate. Hence, if tetrathionate is quantitatively converted into thiocyanate according to Eq. (6), the calibration graph for tetrathionate obtained by measuring the thiocyanate formed from tetrathionate should coincide with that for thiocyanate when the molar concentration scale for tetrathionate is drawn to twice the scale for the thiocyanate concentration. Figure 2 confirms that tetrathionate is completely converted into thiocyanate according to Eq. (6) and that the thiosulfate and trithionate in the sample can be converted into thiocyanate according to Eqs. (4) and (5), respectively.

\section{Stability of iron(III)-thiocyanate complex}

It is known that the absorbance of iron(III)thiocyanate decreases with time because of the reduction of iron(III) by thiocyanate. ${ }^{19}$ The iron(III)- 
thiocyanate can be greatly stabilized by the addition of persulfate, hydrogen peroxide ${ }^{19}$ and nonionic surfactants. ${ }^{20}$ As can be also seen in Table 2, the absorbance of the iron(III)-thiocyanate complex, obtained under Procedure $A$ in which $1 \mathrm{ml}$ of $0.01 \mathrm{M}$ iodine in methanol was not added, gradually decreased with the time of standing. On the other hand, the absorbance remained constant for $2 \mathrm{~h}$ under the conditions of both Procedure B and Procedure IV in which iodine was added as an oxidizing agent. Hence, $1 \mathrm{ml}$ of $0.01 \mathrm{M}$ iodine in methanol was used as a stabilizer for an iron(III)-thiocyanate complex under Procedure IV.

Determination of tetrathionate, thiosulfate, sulfite and trithionate in their mixture

These four sulfur compounds in their mixture give the following equivalents in the four procedures:

$$
\begin{aligned}
& \text { Procedure } \mathrm{I} \equiv \mathrm{S}_{4} \mathrm{O}_{6}{ }^{2-}+\mathrm{S}_{2} \mathrm{O}_{3}{ }^{2-} \\
& \text { Procedure } \mathrm{II} \equiv \mathrm{S}_{2} \mathrm{O}_{3}{ }^{2-} \\
& \text { Procedure III } \equiv \mathrm{S}_{2} \mathrm{O}_{3}{ }^{2-}+2 \mathrm{SO}_{3}{ }^{2-}
\end{aligned}
$$

Table 2 Stability of iron(III)-thiocyanate complex

\begin{tabular}{rccc}
\hline \multirow{2}{*}{$\begin{array}{c}\text { Time/ } \\
\text { min }\end{array}$} & \multicolumn{3}{c}{ Absorbance for $8 \times 10^{-4} \mathrm{M} \mathrm{SCN}^{-}$} \\
\cline { 2 - 4 } & Procedure $\mathrm{A}^{\mathrm{b}}$ & Procedure B & Procedure IV \\
\hline 1 & 0.685 & 0.701 & 0.672 \\
10 & 0.675 & 0.695 & 0.672 \\
20 & 0.666 & 0.695 & 0.674 \\
30 & 0.663 & 0.695 & 0.677 \\
40 & 0.660 & 0.695 & 0.679 \\
60 & 0.652 & 0.695 & 0.676 \\
80 & 0.645 & 0.695 & 0.679 \\
100 & 0.638 & 0.693 & 0.684 \\
120 & 0.635 & 0.693 & 0.680 \\
\hline
\end{tabular}

a. The reagent blank was subtracted.

b. An 1-ml volume of methanolic solution of $0.01 \mathrm{M}$ iodine was deleted from Procedure IV.

c. Each 2-ml volume of $0.15 \mathrm{M}$ sulfite and $0.5 \mathrm{M}$ formaldehyde solutions was deleted from Procedure IV.

\section{Procedure IV $\equiv 2 \mathrm{~S}_{4} \mathrm{O}_{6}{ }^{2-}+\mathrm{S}_{2} \mathrm{O}_{3}{ }^{2-}+\mathrm{S}_{3} \mathrm{O}_{6}{ }^{2-}$.}

The absorbance obtained by Procedure I corresponds to the sum of the amount of tetrathionate [see Eq. (3)] and that of thiosulfate [Eq. (1)] in the mixture. The absorbance obtained by Procedure II, in which the sulfitolysis of tetrathionate was not carried out and the sulfite in the sample was masked by formaldehyde, corresponds only to the amount of thiosulfate in the mixture. The absorbance obtained by Procedure III, in which neither the sulfitolysis of tetrathionate nor the masking of sulfite was carried out, corresponds to the sum of the amount of thiosulfate and twice that of sulfite [Eq. (2)] in the mixture. The absorbance obtained by Procedure IV, in which tetrathionate was converted into both thiosulfate and trithionate, followed by their conversion into thiocyanate by the cyanolysis, corresponds to the sum of the amount of thiosulfate [Eq. (4)], that of trithionate [Eq. (5)] and twice that of tetrathionate [Eq. (6)] in the mixture. The calibration graphs obtained for tetrathionate, thiosulfate and sulfite by, respectively, Procedures I, II and III were in complete agreement with one another when plotted in terms of equivalent concentrations. In addition, the calibration graph for tetrathionate obtained by Procedure IV coincided with those for thiosulfate and trithionate when plotted in terms of equivalent concentrations. Hence, the following equations can be obtained: $\left[\mathrm{S}_{4} \mathrm{O}_{6}{ }^{2-}\right]=\mathrm{I}-\mathrm{II},\left[\mathrm{S}_{2} \mathrm{O}_{3}{ }^{2-}\right]=\mathrm{II},\left[\mathrm{SO}_{3}{ }^{2-}\right]=(\mathrm{III}-$ II) $/ 2$ and $\left[\mathrm{S}_{3} \mathrm{O}_{6}{ }^{2-}\right]=\mathrm{IV}-2 \mathrm{I}+\mathrm{II}$. Here, I, II and III denote the molar concentrations of thiosulfate determined from the calibration graph for thiosulfate shown in Fig. 1 using the absorbance obtained by Procedures I, II and III, respectively. The Roman numeral IV indicates the molar concentration of thiocyanate determined from the calibration graph for thiocyanate shown in Fig. 2 using the absorbance obtained by Procedure IV. Table 3 shows that the proposed method can be successfully applied to the determination of tetrathionate, thiosulfate, sulfite and trithionate

\begin{tabular}{|c|c|c|c|c|c|c|c|}
\hline \multicolumn{4}{|c|}{ Amount taken $/ \mu \mathrm{mol}$} & \multicolumn{4}{|c|}{ Amount found $/ \mu \mathrm{mol}$} \\
\hline $\mathrm{S}_{4} \mathrm{O}_{6}{ }^{2-}$ & $\mathrm{S}_{2} \mathrm{O}_{3}{ }^{2-}$ & $\mathrm{SO}_{3}{ }^{2-}$ & $\mathrm{S}_{3} \mathrm{O}_{6}{ }^{2-}$ & $\mathrm{S}_{4} \mathrm{O}_{6}{ }^{2-}$ & $\mathrm{S}_{2} \mathrm{O}_{3}{ }^{2-}$ & $\mathrm{SO}_{3}{ }^{2-}$ & $\mathrm{S}_{3} \mathrm{O}_{6}{ }^{2-}$ \\
\hline 0.80 & 0.50 & 0.50 & 0.80 & 0.81 & 0.49 & 0.50 & 0.82 \\
\hline 0.70 & 0.70 & 0.45 & 0.80 & 0.71 & 0.69 & 0.44 & 0.82 \\
\hline 0.85 & 0.95 & 0.10 & 0.90 & 0.86 & 0.95 & 0.10 & 0.91 \\
\hline 0.60 & 0.60 & 0.15 & 1.00 & 0.58 & 0.61 & 0.16 & 0.99 \\
\hline 0.20 & 0.30 & 0.75 & 2.00 & 0.20 & 0.30 & 0.75 & 1.99 \\
\hline 1.50 & 0.40 & 0.90 & 2.50 & 1.50 & 0.40 & 0.89 & 2.50 \\
\hline 0.65 & 0.50 & 0.50 & 3.50 & 0.65 & 0.50 & 0.50 & 3.49 \\
\hline 0.40 & 1.50 & 0.25 & 4.50 & 0.41 & 1.50 & 0.26 & 4.48 \\
\hline 0.75 & 0.75 & 0.75 & 5.00 & 0.76 & 0.75 & 0.74 & 5.00 \\
\hline 1.25 & 0.75 & 0.60 & 6.50 & 1.25 & 0.75 & 0.61 & 6.49 \\
\hline 0.95 & 0.30 & 1.00 & 7.00 & 0.95 & 0.30 & 1.00 & 7.00 \\
\hline 0.90 & 1.00 & 0.35 & 7.50 & 0.90 & 1.00 & 0.36 & 7.50 \\
\hline
\end{tabular}

Table 3 Determination of tetrathionate, thiosulfate, sulfite and trithionate mixed in various ratios in a 10-ml solution 
mixed in various ratios with an error less than $\pm 0.02 \mu \mathrm{mol}$.

The precision of the method was obtained from 11 results for a $10-\mathrm{ml}$ aliquot of a sample solution containing $0.75 \mu \mathrm{mol}$ of each species of tetrathionate, thiosulfate and sulfite, and $5 \mu \mathrm{mol}$ of trithionate. The proposed method gave a mean value of $0.76 \mu \mathrm{mol}$ with a standard deviation (SD) of $0.005 \mu \mathrm{mol}$ and a relative standard deviation (RSD) of $0.67 \%$ for tetrathionate, $0.74 \mu \mathrm{mol}(\mathrm{SD}=0.005 \mu \mathrm{mol}$ and $\mathrm{RSD}=0.70 \%$ ) for thiosulfate, $0.74 \mu \mathrm{mol}(\mathrm{SD}=0.004 \mu \mathrm{mol}$ and $\mathrm{RSD}=0.54 \%)$ for sulfite and $5.0 \mu \mathrm{mol}(\mathrm{SD}=0.01 \mu \mathrm{mol}$ and $\mathrm{RSD}=$ $0.22 \%$ ) for trithionate.

Recovery of tetrathionate, thiosulfate, sulfite and trithionate added to natural water samples

Potential matrix interferences from unknown species in natural water samples were investigated using a 10 $\mathrm{ml}$ aliquot of sample solutions followed by the addition of known amounts of tetrathionate, thiosulfate, sulfite and trithionate; the mixture solutions were treated according to Procedures I, II, III and IV. The results are given in Table 4. Iron(III) interferes with Procedures I, II and III because it oxidizes iodide to iodine; iron(II) also interferes with the measurement of absorbance of iron(III)-thiocyanate complex under Procedure IV as a result of the formation of hexacyanoferrate(II). Therefore, the iron(III) present in hotspring water samples, (A) and (C), and the iron(II) in lake water sample were removed by a batch operation ${ }^{21}$ of cation-exchange, in which $1 \mathrm{~g}$ of Amberlite IR-120B (100-200 mesh) was used for each $25 \mathrm{ml}$ of samples. The resin was filtered off by suction with a Millipore SM filter (pore size, $5 \mu \mathrm{m}$ ) prior to the addition of the four sulfur species to the samples. For lake water sample which contained a large amount of iron(II), this cation-exchange procedure was repeated twice. The total polythionates (tetra-, penta- and hexathionate) content in the hot-spring water sample (C) was determined to be $3.2 \times 10^{-5} \mathrm{M}$ by the cyanolysis method ${ }^{22}$ using the standard addition method. When the iron in the samples was removed after the addition of the four sulfur species to the samples, a low recovery only for sulfite was obtained, owing to the evolution of sulfur dioxide from the sulfite in the strong acid media of the samples during the ion-exchange operation. The accuracy of the proposed method was checked by adding varying known amounts of tetrathionate, thiosulfate, sulfite and trithionate to the natural-water samples, the iron in which had been removed. The higher recovery for tetrathionate in hot-spring water (C) can probably be attributed to the presence of higher polythionates, such as penta- and hexathionate in the sample. The other recoveries ranged with an error below $\pm 0.03 \mu \mathrm{mol}$ maximal for tetrathionate, thiosulfate and sulfite and below $\pm 0.2 \mu \mathrm{mol}$ for trithionate. When the method was applied to the natural water samples, the precision was determined from 11 results obtained for a $10-\mathrm{ml}$ aliquot of the hot-spring water sample (A), to which known amounts of tetrathionate $(0.65 \mu \mathrm{mol})$, thiosulfate $(0.50 \mu \mathrm{mol})$, sulfite $(0.50 \mu \mathrm{mol})$ and trithionate $(3.5 \mu \mathrm{mol})$ were added. The proposed method gave a mean value of $0.66 \mu \mathrm{mol}$ with a standard deviation of $0.009 \mu \mathrm{mol}$ and a relative standard deviation of $1.4 \%$ for tetrathionate, $0.50 \mu \mathrm{mol}(\mathrm{SD}=0.006$ $\mu \mathrm{mol}$ and $\mathrm{RSD}=1.1 \%)$ for thiosulfate, $0.50 \mu \mathrm{mol}(\mathrm{SD}=$ $0.007 \mu \mathrm{mol}$ and $\mathrm{RSD}=1.4 \%$ ) for sulfite and $3.4 \mu \mathrm{mol}$ $(\mathrm{SD}=0.03 \mu \mathrm{mol}$ and $\mathrm{RSD}=0.99 \%)$ for trithionate.

Table 4 Recovery of tetrathionate, thiosulfate, sulfite and trithionate added to natural water samples

\begin{tabular}{|c|c|c|c|c|c|c|c|c|c|c|c|}
\hline \multicolumn{4}{|c|}{ Amount taken $/ \mu \mathrm{mol}$} & \multicolumn{4}{|c|}{ Amount found $/ \mu \mathrm{mol}$} & \multicolumn{4}{|c|}{ Recovery, \% } \\
\hline $\mathrm{S}_{4} \mathrm{O}_{6}{ }^{2-}$ & $\mathrm{S}_{2} \mathrm{O}_{3}{ }^{2-}$ & $\mathrm{SO}_{3}{ }^{2-}$ & $\mathrm{S}_{3} \mathrm{O}_{6}{ }^{2-}$ & $\mathrm{S}_{4} \mathrm{O}_{6}{ }^{2-}$ & $\mathrm{S}_{2} \mathrm{O}_{3}{ }^{2-}$ & $\mathrm{SO}_{3}{ }^{2-}$ & $\mathrm{S}_{3} \mathrm{O}_{6}{ }^{2-}$ & $\mathrm{S}_{4} \mathrm{O}_{6}{ }^{2-}$ & $\mathbf{S}_{2} \mathbf{O}_{3}{ }^{2-}$ & $\mathrm{SO}_{3}{ }^{2-}$ & $\mathrm{S}_{3} \mathrm{O}_{6}{ }^{2-}$ \\
\hline \multicolumn{12}{|c|}{ Hot spring water $A^{a}$} \\
\hline 0.85 & 0.95 & 0.10 & 0.90 & 0.86 & 0.95 & 0.10 & 0.75 & 101 & 100 & 100 & 83.3 \\
\hline 0.20 & 0.30 & 0.75 & 2.00 & 0.21 & 0.31 & 0.75 & 1.85 & 105 & 103 & 100 & 92.5 \\
\hline 0.65 & 0.50 & 0.50 & 3.50 & 0.65 & 0.50 & 0.51 & 3.42 & 100 & 100 & 102 & 97.7 \\
\hline \multicolumn{12}{|c|}{ Hot spring water $B^{b}$} \\
\hline 0.85 & 0.95 & 0.10 & 0.90 & 0.87 & 0.96 & 0.10 & 0.76 & 102 & 101 & 100 & 84.4 \\
\hline 0.20 & 0.30 & 0.75 & 2.00 & 0.22 & 0.33 & 0.74 & 1.81 & 110 & 110 & 98.7 & 90.5 \\
\hline 0.65 & 0.50 & 0.50 & 3.50 & 0.68 & 0.51 & 0.51 & 3.33 & 105 & 102 & 102 & 95.1 \\
\hline \multicolumn{12}{|c|}{ Hot spting water $C^{c}$} \\
\hline- & - & - & - & $0.32^{e}$ & - & - & - & - & - & - & - \\
\hline 0.85 & 0.95 & 0.10 & 0.90 & $1.03^{f}$ & 0.93 & 0.10 & 0.83 & 121 & 97.9 & 100 & 92.2 \\
\hline 0.20 & 0.30 & 0.75 & 2.00 & $0.37^{\mathrm{f}}$ & 0.30 & 0.75 & 2.02 & 185 & 100 & 100 & 101 \\
\hline 0.65 & 0.50 & 0.50 & 3.50 & $0.83^{f}$ & 0.49 & 0.50 & 3.56 & 128 & 98.0 & 100 & 102 \\
\hline \multicolumn{12}{|c|}{ Lake waterd } \\
\hline 0.80 & 0.50 & 0.50 & 0.80 & 0.80 & 0.50 & 0.49 & 0.73 & 100 & 100 & 98.0 & 91.3 \\
\hline 0.70 & 0.70 & 0.45 & 0.80 & 0.69 & 0.70 & 0.44 & 0.75 & 98.6 & 100 & 97.8 & 93.8 \\
\hline 0.60 & 0.60 & 0.15 & 1.00 & 0.61 & 0.60 & 0.15 & 0.92 & 102 & 100 & 100 & 92.0 \\
\hline
\end{tabular}

a. Yubatake at Kusatsu-Shirane. b. Yunohanazawa at Hakone. c. Yubatake at Manza. d. Yugama lake water at KusatsuShirane. e. Total polythionates (tetra-, penta- and hexathionate) content. f. Determined as tetrathionate. 
This work was partially supported by a Grant-in-Aid for Scientific Research (No. 56540350) from the Ministry of Education, Science and Culture of Japan. We thank Drs. Minoru Yoshida and Jun-ichi Hirabayashi of Tokyo Institute of Technology for their helpful guidance regarding sampling of hot-spring water and lake-water samples.

\section{References}

1. D. P. Kelly, L. A. Chambers and P. A. Trudinger, Anal. Chem., 41, 898 (1969).

2. T. Mizoguchi and T. Okabe, Bull. Chem. Soc. Jpn., 48, 1799 (1969).

3. J. N. Chapman and H. R. Beard, Anal. Chem., 45, 2268 (1973).

4. A. W. Wolkoff and R. H. Larose, Anal. Chem., 47, 1003 (1975).

5. R. N. Reeve, J. Chromatogr., 177, 393 (1979).

6. C. O. Moses, D. K. Nordstrom and A. L. Mills, Talanta, 31, 331 (1984).

7. B. Takano, M. A. McKibben and H. Barnes, Anal. Chem., 56, 1594 (1984).

8. S. B. Rabin and D. M. Stanbury, Anal. Chem., 57, 1130 (1985).

9. J. Weiss and M. Gobl, Fresenius' Z. Anal. Chem., 320, 439 (1985).
10. R. Steudel and G. Holdt, J. Chromatogr., 361, 379 (1986).

11. T. Koh, K. Taniguchi, Y. Miura and I. Iwasaki, Nippon Kagaku Kaishi, 1979, 348.

12. T. Koh, K. Taniguchi and I. Iwasaki, Bull. Chem. Soc. Jpn., 51, 164 (1978).

13. T. Koh and K. Taniguchi, Anal. Chem., 46, 1979 (1974).

14. T. Koh, A. Wagai and Y. Miura, Anal. Chim. Acta, 71, 367 (1974).

15. T. Koh, Y. Miura and M. Katoh, Talanta, 24, 759 (1977).

16. H. Stamm, M. Goehring and U. Feldmann, Z. Anorg. Allg. Chem., 250, 226 (1942).

17. L. V. Haff, in "The Analytical Chemistry of Sulfur and lts Compounds", ed. J. H. Karchmer, Part I, pp. 225-236, Wiley-Interscience, New York (1970).

18. I. M. Kolthoff, I. B. Sandell, E. J. Meehan and S. Bruckestein, "Quantitative Chemical Analysis", 4th ed., p. 798, Macmillan, London (1969).

19. E. B. Sandell, "Colorimetric Determination of Traces of Metals", 3rd ed., p. 528, Interscience, New York (1959).

20. C. Enkaku and S. Takamoto, Bunseki Kagaku, 34, 365 (1985).

21. T. Ozawa, Nippon Kagaku Zasshi, 87, 576 (1966).

22. T. Koh and K. Taniguchi, Anal. Chem., 45, 2018 (1973).

(Received August 12, 1988)

(Accepted November 25, 1988) 